\title{
Robot-assisted renal surgery: current status and future directions
}

\author{
This article was published in the following Dove Press journal: \\ Robotic Surgery: Research and Reviews \\ 24 May 2016 \\ Number of times this article has been viewed
}

\author{
Manuela Hiess \\ Christian Seitz \\ Department of Urology, Medical \\ University of Vienna, Vienna, Austria
}

Correspondence: Christian Seitz Department of Urology, Medical University of Vienna, Wahringer Gurtel 18-20, I090 Vienna,Austria

Tel +43 I 4040026150

Email drseitz@gmx.at

\begin{abstract}
This paper examines the current role of robot-assisted renal surgery as complex and partial nephrectomies, including vena cava thrombus, combined nephroureterectomies, living donor nephrectomy, autotransplantation, and difficult anatomy as in patients with obesity or adhesions. Indications for robot-assisted renal surgery are comparable to those of conventional laparoscopic approaches. A reduction in the learning curve leads to a stabilization of the procedure and further increases the number of minimally invasive procedures performed. A Medline literature search for publications on the field of robotic kidney surgery has been performed using the MeSH terms: robotic surgical procedures and kidney. Future directions include progress in robotic technology and instrumentation with further miniaturization of robotic procedures as laparoendoscopic single-site interventions and progress in image-guided robotic surgery.

Keywords: minimally invasive, robot, kidney, nephrectomy, pyeloplasty, transplantation
\end{abstract}

\section{Introduction}

Robot-assisted procedures have become an integral part in renal surgery gaining importance mirrored by an increase in publications. The da Vinci robot offers several advances to accelerate the learning curve for nonlaparoscopic surgeons, notably threedimensional (3-D) vision and normal surgical manipulation. The six degrees of freedom can shorten the learning curve for the skilled open, but laparoscopically inexperienced surgeon. ${ }^{1}$ The laparoscopic approach can be limited by the technical challenges of tumor dissection and intracorporal suturing. The robotic approach offers advantages such as magnified stereoscopic vision and fully articulating instruments, which may reduce these technical challenges. Disadvantages of these procedures are the higher costs compared to other procedures.

The focus of robotic renal surgery lies rather in technically demanding procedures than in simple uncomplicated nephrectomies. Advantages of the robotic technology are expected when it comes to the management of renal procedures. These complex procedures are indications where robot-assisted surgery will likely gain more relevance in the future.

\section{Materials and methods}

A Medline literature search for publications on the field of robotic kidney surgery was performed using the MeSH terms: robotic surgical procedures and kidney. Reference lists of retrieved papers were searched for additional references. For robot-assisted partial nephrectomy (RAPN) results, only studies involving $>50$ patients were included. As a review of peer-reviewed studies, no ethical committee approval was obtained. submit your manuscript | www.dovepress.com

Dovepress

http://dx.doi.org/10.2147/RSRR.S71328
Robotic Surgery: Research and Reviews 2016:3 1-12

(c) (i) (-) 2016 Hiess and Seitz. This work is published and licensed by Dove Medical Press Limited. The full terms of this license are available at https://www.dovepress.com/ cc) terms.php and incorporate the Creative Commons Attribution - Non Commercial (unported, v3.0) License (http://creativecommons.org/licenses/by-n/ $/ 3.0$ ). By accessing the work you hereby accept the Terms. Non-commercial uses of the work are permitted without any further permission from Dove Medical Press Limited, provided the work is properly attributed. For permission for commercial use of this work, please see paragraphs 4.2 and 5 of our Terms (https://www.dovepress.com/terms.php). 


\section{Robot-assisted radical nephrectomy}

Renal cell carcinoma has the highest incidence in western countries, representing $2 \%-3 \%$ of all cancers with a trend to a worldwide increase. ${ }^{2}$ Although laparoscopic radical nephrectomy is currently the gold standard for the treatment of a localized renal tumor (cT1-2), with no indications for nephron-sparing surgery (NSS), open radical nephrectomy continues to be performed in large numbers as laparoscopy might not be applicable to all nephrectomies even in experienced hands. The role of robotic radical nephrectomy is still debatable, and criticisms of routine nephrectomy with robotic surgery include the cost, setup time, and longer global operative time over laparoscopic nephrectomy (LN). ${ }^{3}$

A review of 150 nephrectomies demonstrated that the costs of robot-assisted radical nephrectomy (RARN) are comparable to those of $\mathrm{LN}$ when a robot is already present. ${ }^{4}$ In a recent retrospective single institution comparison, the costs of disposable instruments used in LN were comparable to those of the disposables used in RARN, leading to the conclusion that robotic surgery for nephrectomy does not always require higher cost. ${ }^{5}$

\section{Nephrectomy including inferior vena cava thrombectomy}

One potential area of a robotic approach for radical nephrectomy is the field of renal cell carcinoma with an associated thrombus of the inferior cava vein. In this setting, the robotic approach can help overcome the technical difficulties of pure laparoscopy. Only small series exist in the literature. ${ }^{5,6}$ RARN is also feasible in the setting of a horseshoe kidney and/or a renal vein thrombus. ${ }^{7}$ Although laparoscopy is an established treatment for radical nephrectomy, laparoscopic management is uncommon, with only one case report of an entirely laparoscopic management for a short thrombus not requiring inferior vena cava (IVC) cross-clamping. ${ }^{8}$ Recently, Abaza et al ${ }^{9}$ reported 32 cases of robotic nephrectomy among nine surgeons at nine institutions with $n=30$ IVC level II or $\mathrm{n}=2$ IVC level III tumor thrombectomy. The IVC required cross-clamping in 24 cases. The mean operative time was 292 minutes (range 180-411 minutes) with a mean blood loss of $399 \mathrm{cc}$ (range 25-2,000 cc). There were no conversions to open surgery or aborted procedures, and there were three transfusions of 1-3 U. All but two patients ambulated by postoperative day 1 and the mean hospital stay was 3.2 days. The authors concluded that robotic nephrectomy in the setting of IVC tumor thrombus is feasible and can be performed safely. However, it should be kept in mind that their favorable results reported represent a limited experience in selected cases.

Gill et $\mathrm{al}^{10}$ presented the initial series of completely intracorporal robotic levels II and III IVC tumor thrombectomy in seven patients and nine patients, respectively. The median operative time was 4.9 hours (range 4.5-6.3 hours), the median estimated blood loss (EBL) was $375 \mathrm{cc}$ (range 200-7,000 cc), and the median hospital stay was 4.5 days. All surgical margins were negative. There were no intraoperative complications and one postoperative complication (Clavien 3b). At a median 7 months of follow-up, all patients are alive. Compared to level II thrombi, level III cohort had a greater operative time ( 4.5 hours vs 4.9 hours) and blood loss ( $290 \mathrm{cc}$ vs $375 \mathrm{cc}$ ). They concluded that level III IVC thrombectomy is feasible and can be performed efficiently. However, the absence of severe complications in a small series performed by recognized experts in that field does not allow the conclusion whether this approach is more or less safe than the open technique or if outcomes are reproducible.

\section{Oncological outcome}

Compared to open or laparoscopic radical nephrectomy, robotic radical nephrectomy is comparable regarding the oncological outcome (Table 1). Hemal and $\mathrm{Kumar}^{11}$ compared RARN vs LN. In both groups, neither local recurrences nor port-site or distant metastases were detected. However, the

Table I Outcome after RARN

\begin{tabular}{|c|c|c|c|c|c|c|c|}
\hline Study & $\mathbf{n}$ & $\begin{array}{l}\text { Tumor size } \\
(\mathrm{cm})\end{array}$ & $\begin{array}{l}\text { OT (minutes), } \\
\text { median }^{\text {a }}\end{array}$ & EBL & Conversion & PSM & FU (months) \\
\hline Rogers et al ${ }^{14}$ & 35 & 5.1 & 291 & 223 & None & None & 15.7 \\
\hline Hemal and Kumar"l & 15 & 6.7 & 221 & 210 & I:O & NR & 8.3 \\
\hline Boger et al ${ }^{15}$ & 13 & 4.8 & 168 & 100 & $\mathrm{I}: \mathrm{L}$ & NR & NR \\
\hline Lorenzo et al ${ }^{16}$ & 38 & NR & 128 & 274 & None & None & 12 \\
\hline Dogra et al ${ }^{17}$ & 23 & 6.4 & 133 & 270 & 3: 0 & None & 29.4 \\
\hline Petros et $\mathrm{a}^{5, \mathrm{a}}$ & 101 & 8.2 & 172 & 67 & None & I & NR \\
\hline
\end{tabular}

Note: ${ }^{2}$ Ninety cases with renal tumors and 80 cases with malignancies, including complex cases as nine cava thrombectomy and partial additional organ resections.

Abbreviations: EBL, estimated blood loss; FU, follow-up; L, laparoscopic; n, number of patients; NR, not reported; O, open; OT, operation time; PSM, positive surgical margin; RARN, robot-assisted radical nephrectomy. 
number of patients was low with a short follow-up. Similar results were seen in observational cohort studies. Perioperative outcomes were similar. ${ }^{12,13}$

Although randomized data are lacking, the so far largest single-center study from Petros et $\mathrm{al}^{5}$ demonstrated that, regardless of complexity, RARN compared favorably with the large series of LN. Nevertheless, although robotic nephrectomy is a safe and feasible technique, there is no clear advantage shown in literature compared to the LN approach. ${ }^{6}$ However, advantages of the robotic approach compared to a laparoscopic approach may be a better retraction of the kidney when using the fourth robotic arm and, thus, a potential reduction in operation time and an easy ligation of the kidney vessels similar to the open approach.

\section{Complications}

Compared to open and LN, RARN is comparable regarding the peri- and postoperative complications. ${ }^{11}$ In the largest to date series, including 101 RARN cases, Clavien grades III-V complications occurred in $5 \% .{ }^{5}$ No patient had to be converted to open surgery. This compares well with $\sim 5 \%$ conversion rates in the larger reported $\mathrm{LN}$ series. The rate of open conversions found in 200 laparoscopic nephrectomies was $13.8 \%$ for tumors $>10 \mathrm{~cm} .{ }^{18}$ The robotic series from Petros et $\mathrm{al}^{5}$ included 24 patients with tumors $>10 \mathrm{~cm}$ and no conversions. Ivey et al investigated the conversion rates in different laparoscopic renal surgery techniques. The conversion rates were $1.8 \%$ in robotic cases, $10.4 \%$ in conventional laparoscopic cases, $17.1 \%$ in hand-assisted laparoscopic cases, and $15.8 \%$ in retroperitoneoscopic cases. ${ }^{19}$ However, the potential benefit of adding robotics to uncomplicated LN is not proven yet. Indications for complex cases of RARN should be investigated in experienced hands, such as the invasion of adjacent organs and the presence of an associated IVC thrombus.

\section{Robot-assisted partial nephrectomy}

NSS is currently considered as the gold standard of treatment for tumors $<4 \mathrm{~cm}$ (T1a). The main advantages of minimally invasive NSS are lower blood loss and thus transfusion rates, lower postoperative pain, and faster recovery time. Open partial nephrectomy (OPN) has been the reference standard for the management of the small renal mass regarding a potential benefit for functional and oncological outcomes. The morbidity of OPN, such as open flank incision and muscle cutting, has led to significant advances in minimally invasive NSS with the laparoscopic partial nephrectomy (LPN) as a reference standard. ${ }^{20}$ High technical skills are necessary for LPN, possibly leading to an underutilization of these procedures. ${ }^{21}$ The laparoscopic approach can be limited by the technical challenges of tumor dissection and intracorporal suturing.

According to recent EAU guidelines, minimally invasive procedures, such as LPN and RAPN, are alternatives to OPN based on surgeon's expertise and skills. ${ }^{2}$ Dissemination of RAPN is increasing. The shorter learning curve with comparable results is one explanation for this development. ${ }^{1,22}$

Master-slave systems as the da Vinci system demonstrate a steep learning curve. Several new advances have emerged to accelerate the learning curve for nonlaparoscopic surgeons, notably 3-D vision and normal surgical manipulation. Notably, the six degrees of freedom can shorten the learning curve for the skilled open, but laparoscopically inexperienced surgeon. ${ }^{23}$ The robotic approach offers advantages, such as magnified stereoscopic vision up to $12 \times$ and simplified maneuvers with the EndoWrist (Intuitive Surgical, Sunnyvale, CA, USA) and fully articulating instruments, which may reduce these technical challenges. These advantages lead to a steeper learning curve compared to conventional laparoscopy. ${ }^{24}$ According to Mottrie et al, a good level of proficiency on the console, blood loss, and warm ischemic time (WIT) is reached after 25-40 interventions. . $22,25^{2}$

To address the levels of expertise and reduce the complications and optimize the outcomes, treatment decisions for renal malignancies need a standardized description of tumor anatomy. Surgical decision-making and data set comparisons would be significantly enhanced by a consistent, reproducible system.

Different systems, such as the Radius (tumor size), Exophytic/endophytic properties of the tumor, Nearness of tumor deepest portion to the collecting system or sinus, Anterior (a)/posterior (p) descriptor and the Location relative to the polar line (RENAL) score, ${ }^{26}$ the preoperative aspects and dimensions used for an anatomical classification, ${ }^{27}$ centrality index, ${ }^{28}$ and contact surface area, ${ }^{29}$ are used for preoperative planning, which is necessary for optimizing operative outcomes. A literature review of renal surgical anatomy and surgical strategies for partial nephrectomy has been recently published by Klatte et al. ${ }^{30}$

The potential negative impact of ischemia on renal function led to the development of techniques to minimize or completely avoid renal ischemia, such as minimally ischemic and off-clamp partial nephrectomies. However, these techniques are technically demanding and require experience in partial nephrectomy. Minimally ischemic and off-clamp 
partial nephrectomies show an increased risk for higher blood loss and a compromised visualization of the surgical field, possibly resulting in positive margins. Known minimally ischemic techniques are preoperative superselective transarterial embolization, selective clamping, zero-ischemia partial nephrectomy with controlled hypotension, and parenchymal clamping.

Simone et $\mathrm{al}^{31}$ demonstrated in a review of 52 studies that off-clamp partial nephrectomy is commonly applied to small and peripheral renal tumors, whereas minimally ischemic methods are best used for hilar and medially located tumors. Selective clamping of the tumor-feeding artery is one of the minimally ischemic techniques. In this approach, global ischemia can be avoided (Figure 1A-D). For better visualization, robotic near-infrared fluorescence with the administration of indocyanine green confirms the devascularized area and helps determining the resection area. ${ }^{32}$ One of the advantages of using indocyanide green is to confirm that the tumor is truly ischemic.

This method demonstrated comparable perioperative outcomes to on-clamp partial nephrectomy (operative time
176.1 minutes vs 195.6 minutes, WIT 20.4 minutes vs 22.9 minutes, and EBL $211 \mathrm{~mL}$ vs $207 \mathrm{~mL}$ ) in a matched-pair analysis of 42 robotic partial nephrectomy cases with nearinfrared fluorescence selective clamping compared to 42 on-clamp partial nephrectomy cases. A significantly lower decrease in estimated glomerular filtration rate (eGFR) at discharge was demonstrated $(1.9 \%$ vs $16.8 \%, P<0.01){ }^{31}$ Akca et al recently investigated the possible detrimental effects of clamping main vs segmental renal arteries for the achievement of renal global ischemia during RAPN. Patient groups consisted of cases where one main renal artery (or hilum) was clamped vs cases where multiple arteries or multiple branches of arteries were individually clamped. ${ }^{33}$ Including 579 patients, they found that blood loss and WIT were comparable between both groups. There was no statistically significant difference between the groups regarding postoperative complications (19\% vs $12.6 \%$ ). On multivariable analysis, WIT and preoperative eGFR remained the only significant predictors of early eGFR preservation. ${ }^{33}$

Desai et al retrospectively compared a total of 52 consecutive patients undergoing robotic partial nephrectomy
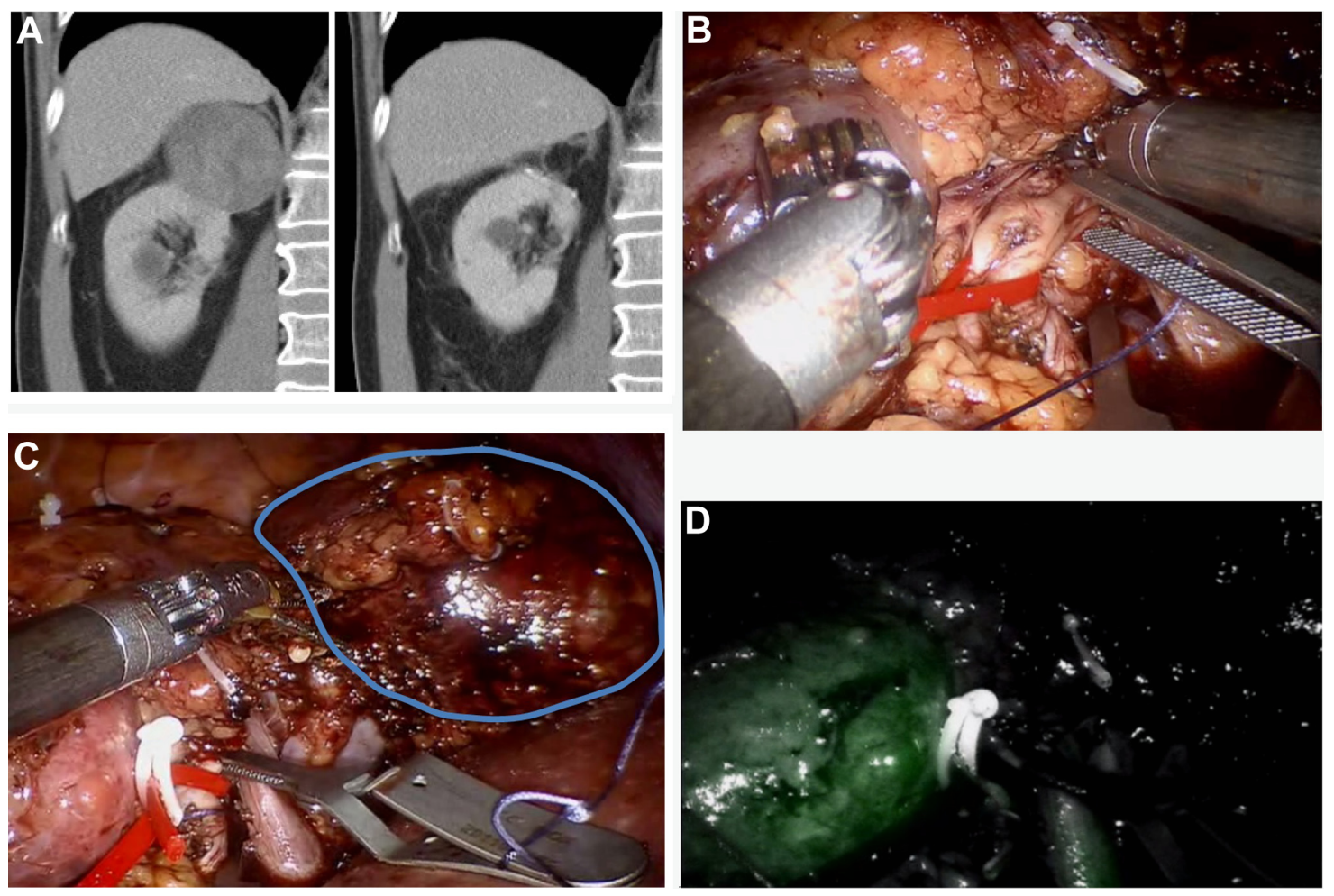

Figure I Selective clamping of three arterial branches supplying the dorsal right-sided $6 \mathrm{~cm}$ upper pole RCC.

Notes: (A) Contrast-enhanced CT image demonstrating the upper pole $6 \mathrm{~cm}$ tumor of the right kidney preoperative and 6 months postoperative. (B) A dorsal segmental branch is clamped. The renal artery is put on tension with a vessel loop to improve exposure of the anterior upper pole arterial branches and a second bulldog is prepared to clamp. (C) Selective clamping of another two arterial branches supplying the dorsal right-sided $6 \mathrm{~cm}$ upper pole RCC. The lower pole is visible on the left side of the image. Gerotas fascia is covering the mid portion of the kidney. The tumor is encircled on the right side. (D) After application of indocyanine green, the perfusion of the lower pole of the kidney is visible, whereas the upper pole tumor is not perfused and therefore not visible.

Abbreviations: RCC, renal cell carcinoma; CT, computed tomography. 
with superselective vs main artery clamping in 61 patients. $^{34}$ All margins were negative, and both groups had similar perioperative complication rates, although the postoperative transfusion rate was significantly higher (24\% vs $6 \%)$ in the superselective group, but differences decreased with experience. The superselective devascularization resulted in higher glomerular filtration rates ( $11 \%$ vs $17 \%$ loss). The authors confirm the noninferiority of this demanding technique compared to main artery clamping during RAPN. This technique is probably best in selected patients requiring urgent preservation of renal function.

\section{Functional outcome}

The main challenge of PN regarding the functional outcome is to keep the ischemic time low. The limit for WIT is 20 minutes, and cold ischemic time should be kept as short as possible - at best within 35 minutes - but can be prolonged up to 2 hours. To date, there is no dose-response curve available to predict the risk of kidney damage caused by renal arterial clamping. ${ }^{35}$

Although the resection of small tumors without clamping the kidney vessels provides an oncologically adequate surgery and minimizes the perioperative complications or loss of renal function, intraoperative ischemia often becomes necessary. Ischemia diminishes intraoperative renal hemorrhage and improves access to the collecting system and also allows better visualization of the tumor extent and complete tumor resection. ${ }^{35}$ However, the number of arterial vessels clamped during the procedure and clamping of the renal vein at the time of arterial clamping were not the predictors of early eGFR preservation. ${ }^{33}$
Even minor loss of kidney function can reduce life expectancy and increase cardiovascular morbidity. Thus, preservation of renal function is the main challenge besides the oncological outcome. ${ }^{35}$ Results of RAPN outcome of selected studies including $>50$ patients are summarized in Table 2.

In a multicenter matched-pair comparison by Kim et al, ${ }^{47}$ a total of 1,032 patients were included for evaluation. This resulted in 195 LPNs matched to 195 RAPNs. Operative time $(P<0.001)$ and WIT $(P<0.001)$ were significantly shorter in the RAPN group. No significant differences were found in the overall change in eGFR $(P=0.768)$ or positive surgical margin (PSM; $P=0.653$ ). Similarly, surgical outcomes after robotic or pure laparoscopic PN in moderate-to-complex renal tumors resulted in a significantly lower EBL and a shorter WIT in the robotic group. ${ }^{48}$ Two meta-analyses demonstrated comparable perioperative outcomes and shorter WIT for RAPN. ${ }^{49,50}$

A systematic review by Choi et al, ${ }^{25}$ including 23 studies and a total of 2,240 patients, showed a significantly lower rate of conversion to open surgery $(P=0.02)$ and radical surgery ( $P=0.0006)$, shorter WIT $(P=0.005)$, smaller change of eGFR $(P=0.03)$, and shorter length of stay $(P=0.004)$ in the RAPN group vs the LPN group. There were no significant differences regarding the operative time $(P=0.35), \mathrm{EBL}(P=0.76)$, change of serum creatinine $(P=0.65)$, and positive margins $(P=0.75)$.

Partial nephrectomy for tumors $>4 \mathrm{~cm}$ may pose additional technical challenges during surgery. Patel et $\mathrm{al}^{42}$ published data for 71 consecutive patients who underwent transperitoneal RAPN-56 patients with tumors $<4 \mathrm{~cm}, 15$ patients with

Table 2 RAPN results regarding tumor size, operation time, WIT, EBL, and PSM rates of selected studies including $>50$ patients

\begin{tabular}{|c|c|c|c|c|c|c|}
\hline Study & $\mathbf{N}$ & $\begin{array}{l}\text { Mean tumor } \\
\text { size }(\mathrm{cm})\end{array}$ & $\begin{array}{l}\text { Mean operative } \\
\text { time (minutes) }\end{array}$ & $\begin{array}{l}\text { Mean WIT } \\
\text { (minutes) }\end{array}$ & $\begin{array}{l}\text { Mean EBL } \\
(\mathrm{mL})\end{array}$ & $\begin{array}{l}\text { PSM } \\
\text { (\%) }\end{array}$ \\
\hline Benway et $\mathrm{al}^{36}$ & 129 & 2.9 & 189 & 19.7 & 155 & 4 \\
\hline Mottrie et $\mathrm{al}^{22}$ & 62 & 2.8 & 91 & 20 & 140 & 2 \\
\hline Benway et $\mathrm{al}^{37}$ & 183 & 2.9 & 210 & 23.9 & 132 & 3.8 \\
\hline Dulabon et $\mathrm{al}^{38, \mathrm{a}}$ & 446 & $2.9-3.5$ & $187-194$ & $19.6-26.3$ & $208-262$ & 1.6 \\
\hline Spana et $\mathrm{al}^{39}$ & 450 & 2.91 & 188 & 20.2 & 213 & NR \\
\hline Scoll et $\mathrm{al}^{40}$ & 100 & 2.8 & 206 & 25.5 & 127 & 5.7 \\
\hline Rogers et al ${ }^{102}$ & 148 & 2.8 & 197 & 27.8 & 183 & \\
\hline Haber et $\mathrm{al}^{4 \mathrm{I}}$ & 75 & 2.8 & 200 & 18.2 & 323 & 0 \\
\hline Patel et $\mathrm{al}^{42}$ & 71 & $2.1-5$ & $238-275$ & $20-25$ & 100 & 4.2 \\
\hline Petros et $\mathrm{al}^{43}$ & 95 & $2.3-2.5$ & $246-250$ & $|6-2|$ & $100-150$ & NR \\
\hline Lorenzo et al $^{16}$ & 65 & NR & $|7|$ & NR & 243 & 9.2 \\
\hline Naeem et $\mathrm{al}^{44}$ & 97 & $2.3-2.5$ & $242-265$ & $22.5-26.5$ & $100-150$ & 2 \\
\hline Wang et $\mathrm{al}^{45}$ & 81 & 3.8 & 136 & 20.5 & 197 & 1.2 \\
\hline Ting et $\mathrm{al}^{46}$ & 76 & 3.5 & 240 & 8 & NR & 1.3 \\
\hline
\end{tabular}

Note: aNonhilar (405) vs hilar ( $n=4$ I) tumors.

Abbreviations: EBL, estimated blood loss; NR, not reported; PSM, positive surgical margin; RAPN, robot-assisted partial nephrectomy; WIT, warm ischemic time. 
tumors $>4 \mathrm{~cm}$ (mean size $5.0 \mathrm{~cm}$; range $4.1-7.9 \mathrm{~cm}$ ). The median WIT was longer for tumors $>4 \mathrm{~cm}$ (25 minutes vs 20 minutes; $P=0.011$ ), the median total operative time was also longer for larger tumors (275.5 minutes vs 238 minutes; $P=0.068$, no statistical significance).

Although prospective evidence would be ideal, clinical trial comparisons with LPN and OPN will be fraught with accrual challenges and are not expected in the near future. ${ }^{51}$

\section{Oncological outcome}

The oncological outcome after laparoscopic and OPN is similar regarding positive margins or recurrence rates. ${ }^{52}$

In the large unicentric studies, positive margins are described in $1.5 \%-5.7 \%$ of patients with RAPN, which is comparable to the positive margins rates of LPN and OPN. ${ }^{51}$ The oncological follow-up is too short to allow a retrospective analysis of the long-term data. Gorin et $\mathrm{al}^{53}$ showed an upstaging from cT1 to cT3a in $4.8 \%$. The median follow-up was 17.3 months (range 8-30 months). After 2 years, a local recurrence rate for $\mathrm{pT} 1-2$ and $\mathrm{pT} 3 \mathrm{a}$ tumors was shown in $0.8 \%$ and $8.2 \%$, respectively $(P=0.003)$. Risk factors for an upstaging are complex tumors, large tumor diameters, and a hilar tumor localization.

PSMs after RAPN were evaluated in a multicenter study including 943 RAPNs. ${ }^{54}$ A low prevalence of $2.2 \%(n=21)$ PSMs after RAPN was reported. These patients presented with 18.4-fold higher recurrence and metastasis rates. These results are based on a small number of margin-positive patients and need to be confirmed in a larger series.

Khalifeh et al $^{55}$ investigated 204 patients with a mean follow-up of 3 years. The overall survival (OS) was $97 \%$ at 3 years and $90 \%$ at 5 years. The recurrence-free survival (RFS) was $98.9 \%$ at 3 years and 5 years; cancer-specific survival (CSS) was reported to be as high as 99\%. A 20\% upstaging of chronic kidney disease postoperatively was demonstrated.

\section{Outcome reporting systems}

To summarize the perioperative outcomes of RAPN, two systems have been described. Lista et $\mathrm{al}^{56}$ described the margin, ischemia, and complications system (MIC) to report the perioperative outcomes of RAPN. The study population consisted of 339 patients who underwent RAPN for cT1 tumors at three centers. Ideal WIT was considered as $<20$ minutes. Safety was defined as the absence of major complications (Clavien classification grades III and IV). ${ }^{57}$ Cancer control was defined as the absence of PSMs. The achievement of MIC is the fulfillment of all three outcomes. The median WIT was 17 minutes (range 7-51 minutes) with
WIT of $>20$ minutes in 88 cases $(26 \%)$. PSMs were observed in 22 patients $(6.5 \%)$, and the major complication rate was $3.8 \%$. The overall MIC rate was $67 \%$. Both continuously and categorically coded preoperative aspects and dimensions used for anatomical scores were independent predictors of MIC achievement.

A similar reporting system is the Trifecta system. Zargar et $\mathrm{al}^{58}$ retrospectively reviewed 2,392 consecutive cases of RAPN and LPN performed in five high-volume centers from 2004 to 2013. The Trifecta system was defined as negative surgical margins, no perioperative complications, and a WIT of $<25$ minutes. They also defined a new measure of optimal outcome, pentafecta of outcomes, such as the presence of Trifecta plus no chronic kidney disease and 90\% eGFR preservation. Inclusion criteria were met by 1,185 RAPNs and 646 LPNs. The RAPN group demonstrated a reduced WIT (18 minutes vs 26 minutes) and a lower overall complication rate $(16.2 \%$ vs $25.9 \%$ ) and PSM rate (3.2\% vs 9.2\%). The Trifecta rate was significantly higher for RAPN (70\% vs 33\%), and the pentafecta rate was achieved in $38.5 \%$. Both systems can be helpful in the future; however, external validation is needed.

\section{Perioperative complications}

Complications are classified according to the Clavien-Dindo classification of complications. ${ }^{57}$ RAPN is a safe surgical technique with an intraoperative complication rate between $1.4 \%$ and $2.9 \%{ }^{47}$ In a large multicenter series with 886 patients, Tanagho et al demonstrated that RAPN is comparable to other nephron-sparing modalities regarding the complications. The postoperative complication rate was $13 \%$, which is comparable to other LPN studies. ${ }^{39,59,60}$ Benway et $\mathrm{al}^{36}$ showed no significant differences of complication rates between 129 patients with RAPN and 118 patients with LPN (8.5\% vs $10.2 \%)$.

\section{Specific complications of partial nephrectomy}

Typical complications of RAPN are bleeding, urinoma, and acute renal failure due to WIT. The larger series show bleeding requiring transfusion in 3.7\%-4.2\%. Pseudoaneurysms are complications after RAPN predominantly seen in central localized tumors with an incidence between $0.2 \%$ and $3.8 \%$. $^{39,59,61}$

There is a correlation found between perioperative complications and tumor size. ${ }^{60,61}$ However, the main factor to minimize the perioperative complications, despite better technical equipment and 3-D vision, is the experience of the surgeon. ${ }^{62}$ 


\section{Robot-assisted nephroureterectomy}

Upper tract urothelial carcinoma (UTUC) has an estimated incidence of $3 \%-5 \%$ of all urothelial cancers. ${ }^{63}$ Radical nephroureterectomy, including bladder cuff excision, is the current gold standard in the management of high-grade disease. The safety and feasibility of a minimally invasive approach in organ-confined disease vs open nephroureterectomy has been demonstrated in a randomized controlled trial, while its effectiveness in patients with advanced stage diseases remains to be proven. ${ }^{64}$

Rose et $\mathrm{a}^{65}$ reported the first robot-assisted nephroureterectomy (RANU) for left ureteral urothelial carcinoma in 2006. Lee et al ${ }^{66}$ implemented a unique port placement strategy based on a modified paramedian line, which allowed sufficient access to both the upper abdomen and the deep pelvis for RANU with bladder cuff excision and concomitant lymphadenectomy. Yang et $\mathrm{al}^{67}$ included 20 patients with UTUCs undergoing RANU by redocking the robot after the nephrectomy for the excision of the distal ureter and bladder cuff. Recently, Aboumohamed et a ${ }^{68}$ reported the oncological outcomes of initial 65 patients undergoing RANU with bladder cuff excision using a single docking technique. Different techniques of bladder cuff excision exist, and since randomized controlled trials are lacking, no recommendation for a certain technique can be given. Xylinas et $\mathrm{al}^{69}$ studied the management of the distal ureter during radical nephroureterectomy. In patients undergoing the transvesical approach, the extravesical approach, and the endoscopic approach, there was no difference in terms of RFS, CSS, and OS. Patients who underwent the endoscopic approach were at significantly higher risk of intravesical recurrence compared to those who underwent the transvesical $(P=0.02)$ or extravesical approaches $(P=0.02)$; the latter two groups did not differ from each other $(P=0.40){ }^{69}$

\section{Perioperative outcome}

In 43 RANUs performed at three institutions for UTUC, ${ }^{70}$ the mean operating time was 247 minutes (range $128-390$ minutes), the mean blood loss was $131 \mathrm{~mL}$ (range $10-500 \mathrm{~mL}$ ), and the median (range) length of stay was 3 days (range 2-87 days). None of the procedures were converted or required blood transfusions. Lymphadenectomy was performed on 16 of the 20 patients, with a mean yield of 14.1 (range 2-35) lymph nodes removed. There were 14\% postoperative complications: bleeding requiring a blood transfusion (Clavien II), splenic bleeding (Clavien IV), two cases of pneumonia (Clavien II), and two cases of rhabdomyolysis (Clavien II and IV). Yang et al reported that the mean operative time was $251.6 \pm 126.7$ minutes (range 110-540 minutes) and the mean EBL was $50.0 \pm 42.9 \mathrm{~mL}$ (range 10-200 mL). Aboumohamed et al reported only $6.6 \%(n=3)$ of one Clavien 2 and two Clavien 3a complications.

\section{Oncological outcome}

In the study from Pugh et al, pathology was pTa in nine patients, pT1 in 14 patients, pT2 in three patients, pT3 in 15 patients, and pT4 in two patients. Lymph node dissection was performed in $51 \%$ with a mean lymph node count of eleven (range 4-23). Nine recurrences (six bladder recurrences, two within the retroperitoneum, and one in the contralateral collecting system) have been found to date on routine surveillance with a mean follow-up of 9 months. ${ }^{70}$ Yang et al found 19 high-grade urothelial carcinoma and one low-grade urothelial carcinoma: staged Ta for three, T1 for five, T2 for five, and T3 for seven. There were no PSMs. After a mean follow-up of 14.7 months (range 2-34 months), three bladder recurrences developed, and additional four patients developed metastatic disease. The CSS rate was $75 \%$. It should be considered that, Taiwan having a high incidence rate of UTUC, the conclusions that can be drawn for comparative effectiveness with other techniques are limited. ${ }^{67}$ The recent study by Aboumohamed, including 65 RANUs with bladder cuff excision pathology, demonstrated $65 \%$ of pT2 stage or lower, $28.3 \%$ of pT3 stage, and $6.7 \%$ of pT4 stage. High-grade pathology was present in $85 \%, 13.3 \%$ with concomitant CIS and $30 \%$ with lymphovascular invasion. The median follow-up was 25.1 months (range 6-68.9 months). At 2 years and 5 years, the OS was $86.9 \%$ and $62.6 \%$, the CSS was $92.9 \%$ and $69.5 \%$, and the RFS was $65.3 \%$ and $57.1 \%$, respectively. A total of 23 patients experienced disease recurrence, while 15 patients developed bladder recurrences: 12 had isolated bladder recurrences and eight patients developed metastatic disease. Only lymphovascular invasion was associated with a reduced CSS on multivariate analysis $(P=0.048){ }^{68}$

In view of the current evidence, RANU is a safe and feasible minimally invasive alternative to laparoscopic and open procedures for UTUCs. The sutured closure of the bladder cuff and regional lymphadenectomy are facilitated with the use of robot-assisted surgery. Prospective randomized controlled studies comparing open, conventional laparoscopic, or hybrid open/laparoscopic techniques to assess the clinical efficacy are lacking. Another major limitation is the short follow-up in current studies. RANU for UTUC demonstrated satisfactory oncological results on intermediate-term follow-up. However, early experience appears promising, but long-term outcomes will be required to assess for true efficacy. 


\section{Robot-assisted living donor nephrectomy}

For living donor nephrectomy, the use of a robotic system is potentially beneficial. Again, laparoscopy is associated with a significant learning curve. ${ }^{71,72}$ The largest series to date has been performed hand-assisted 273 robotically assisted left donor nephrectomies. ${ }^{73}$ The mean hospital stay was 2.3 days (range 1-8 days) and the mean blood loss was $82 \mathrm{~mL}$ (range $10-1,500 \mathrm{~mL}$ ). The operative time was 103 minutes for the last 70 cases. Giacomoni et $\mathrm{al}^{74}$ compared hand-assisted robotic nephrectomy using the technique described by Horgan et al vs totally robotic nephrectomy. Each patient suitable for living donor nephrectomy was suitable for the minimally invasive approach with the only relative contraindication of more than one previous abdominal procedure. ${ }^{75}$ Intraoperative bleeding was similar between both groups ( $90 \mathrm{~mL}$ vs $100 \mathrm{~mL}$ ). Switching to the open procedure was never required. The median operative time was not significantly longer (175 minutes vs 250 minutes). The median WIT was significantly shorter in the hand-assisted group than in the robotic group (2.3 minutes vs 5.1 minutes). Similarly, Horgan et $\mathrm{al}^{73}$ could demonstrate WITs of $<2$ minutes and a graft survival rate of $98 \%$. These results remained stable even in the presence of vessel anomalies.

\section{Complications}

Horgan et al reported a significant decrease in complications after the first 74 cases. The 1-year patient survival rate was $100 \%{ }^{73}$ Giacomoni et al reported only one Clavien 2 complication with a post-discharge subocclusion syndrome. No patient developed Clavien 3 or higher complications. ${ }^{74}$ Hubert et al reported their experience of robot-assisted living donor nephrectomies stating its safety. All nephrectomies were carried out without complications and with minimal blood loss. The mean surgery time was 181 minutes. The average WIT and cold ischemic time were 5.84 minutes and 180 minutes, respectively. ${ }^{76}$

\section{Renal function}

All donors demonstrated a normalized renal function within 9 days of surgery. No cases of graft loss were observed, and between $94 \%$ and $100 \%$ of transplanted kidneys had an immediate function. ${ }^{73,74,76}$ They concluded that using a robotic-assisted approach, living kidney recovery is a safe and effective procedure enhancing the laparoscopic skills. It is the method of choice for surgeon's ergonomic comfort and donors' safety. ${ }^{74,76}$

\section{Robot-assisted kidney transplantation}

Robotic approaches to renal transplantation have shown promising results compared to open renal transplantation. ${ }^{77}$ A variety of techniques are described. ${ }^{77-81}$ A significant reduction in wound infections in patients with morbid obesity vs standard open renal transplantation ( $0 \%$ vs $28.6 \%$, $P<0.004)$ was observed compared to laparoscopic renal transplantation by Modi et a ${ }^{82}$ Similarly, Tzvetanov et al performed robot-assisted kidney transplantation (RAKT) in patients with morbid obesity as the increased risk of infection in open surgery negatively impacts the graft survival. ${ }^{83,84}$ In a matched-pair cohort of 28 patients each, there were no surgical site infections in the robotic group compared to $28.6 \%$ in the control group. However, patient and graft survival were comparable. ${ }^{77}$ After 135 RAKTs, the authors report no surgical site infections in the robotic group in patients with a mean body mass index (BMI) of $43 \mathrm{~kg} / \mathrm{m}^{2}{ }^{83}$ Sood et a ${ }^{85}$ also noted similar reductions in analgesic use, blood loss, and complications in patients undergoing robot-assisted transplantation vs open renal transplantation. RAKT seems to be a safe approach with a reduced complication rate in patients with obesity.

\section{Intracorporal renal autotransplantation}

Gordon et al presented a complete robot-assisted intracorporeal renal autotransplantation. The WIT was 2.3 minutes, and cold ischemia was achieved by intracorporeal hypothermic renal perfusion for 95.5 minutes. The venous and arterial anastomosis times were 17.3 minutes and 21.3 minutes, respectively. The EBL was $<50 \mathrm{~mL}$. There were no complications, and the patient was discharged home on postoperative day 1 after normal Doppler renal ultrasound. ${ }^{86}$ Postoperative renal scan at 6 weeks, intravenous urogram at 8 weeks, and computerized tomography urography at 5 months revealed normal function and successful ureteral reconstruction. A completely intracorporal renal autotransplantation is a feasible approach to renal preservation after major ureteral injury for selected patients and in the hands of experienced robotic surgeons. ${ }^{86}$ However, these approaches, although promising, should be considered as experimental at present.

\section{Robotic-assisted pyeloplasty}

The ureteropelvic junction obstruction (UPJB) is the most common congenital anomaly of the ureter. An open pyeloplasty was the gold standard of treatment for a long time until the first laparoscopic pyeloplasty was performed in 1993.

This approach led to a comparable success rate together with less morbidity. Gettman et al ${ }^{87}$ reported the first robot-assisted 
pyeloplasty (RAPP) series in 2002. Unfortunately, prospective randomized data comparing laparoscopic and robotic pyeloplasties do not exist. The largest retrospective multicenter study was published by Lucas et al with 259 included cases (274 laparoscopic cases and 465 robotic cases). There were no significant differences in operative time, complication rate, and radiographic success at 6 months. ${ }^{88}$ The feasibility and efficacy of RAPP has been demonstrated by both the retroperitoneal and the transperitoneal approaches. ${ }^{89}$ Overall, 55 patients underwent retroperitoneoscopic and transperitoneal RAPPs for UPJO. The overall success rate using the diuretic renal scan and/or imaging techniques was $96 \%$ with two recurrences in the retroperitoneal group with a follow-up of at least 6 months. In adults, a minimally invasive approach is the gold standard for primary pyeloplasty. The robotic approach itself shows no distinct advantage regarding clinical and functional outcomes. ${ }^{90}$

\section{Future directions Image-guided robotic surgery}

Image-guided surgery aims at improving anatomic visualization. Computed tomography (CT), magnetic resonance imaging (MRI) and ultrasound (US) are more suitable for image-guided surgery (IGS) because of their deeper penetration compared to optical visualization. However, softtissue deformation makes it difficult to implement IGS in robotic urology. In 2012, Ukimura et al $^{91}$ first reported the 3-D reconstructions of renovascular-tumor anatomy for zero ischemia in RAPN. Since then, several reports on 3-D imaging reconstruction offering accurate anatomical identification of important intrarenal structures were published. ${ }^{92-95}$ At present, feasibility of IGS is limited and requires randomized controlled trials for assessing its feasibility on clinical outcome. ${ }^{96}$

Contrast-enhanced ultrasound combines contrast consisting of microbubbles with ultrasound. Referring to a recent systematic review by Alenezi and Karim, ${ }^{97}$ it has the potential to facilitate imaging of renal tumors during RAPN, especially in patients with impaired renal function who cannot be given the other contrast agents used in current imaging techniques. Contrast-enhanced ultrasound has the potential to aid in selective arterial clamping and to image the renal microvasculature, without affecting renal function.

\section{Robotic laparoendoscopic single-site surgery}

Laparoendoscopic single-site (LESS) surgery has been introduced as a next step to further miniaturize laparoscopic renal procedures. Difficulties interfering with the dissemination of
LESS include an in-line view with clashing of instruments and loss of triangulation. To overcome these obstacles, robotic LESS (R-LESS) fits instruments and camera within a singlesite port and uses remote center technology to minimize cannula collisions, arm interferences, and port-site movement. The da Vinci system software (Intuitive Surgical, Inc. Sunnyvale, CA, USA) automatically detects and reassociates user's hands with the instrument tips to create collision-free movements through crossed trokars. The first clinical application of R-LESS was performed by Kaouk and Goel in 2009.98 Since then, there have been additional reports of R-LESS, including prostatectomy, radical nephrectomy, partial nephrectomy, pyeloplasty, and other urologic procedures. ${ }^{99,100}$ Recently, platform-specific instruments (VeSPA; Intuitive Surgical, Sunnyvale, CA, USA) have been developed for LESS surgery. ${ }^{101}$ Although R-LESS is a feasible technique with good cosmetic results, multicentric studies are required to gain more evidence regarding the effectiveness, feasibility, and cost considerations of this technique.

\section{Conclusion}

Overall, robotic kidney surgery is a technique in evolution, and the prospects of robotic staplers, EndoWrist ligature, and robotic single-port techniques may further increase robotic penetration in minimally invasive surgery.

In recent comparative studies, robotic renal surgery is associated with favorable perioperative outcomes when compared with the conventional laparoscopic procedures. Further studies are needed to compare the results of complex robotic cases with open procedures. The current high cost is the most prohibitive factor for its widespread distribution.

\section{Disclosure}

The authors report no conflicts of interest in this work.

\section{References}

1. Hanzly M, Frederick A, Creighton T, et al. Learning curves for robot-assisted and laparoscopic partial nephrectomy. J Endourol. 2015;29(3):297-303.

2. Ljungberg B, Bensalah $\mathrm{K}$, Canfield $\mathrm{S}$, et al. EAU guidelines on renal cell carcinoma: 2014 update. Eur Urol. 2015;67(5):913-924.

3. Yang DY, Monn MF, Bahler CD, Sundaram CP. Does robotic assistance confer an economic benefit during laparoscopic radical nephrectomy? J Urol. 2014;192(3):671-676.

4. Roos FC, Thomas C, Neisius A, Nestler S, Thüroff JW, Hampel C. Robotisch assistierte laparoskopische partielle Nephrektomie Funktionelle und onkologische Ergebnisse [Robot-assisted laparoscopic partial nephrectomy: functional and oncological outcomes]. Urologe A 2015;54(2):213-218. German.

5. Petros FG, Angell JE, Abaza R. Outcomes of robotic nephrectomy including highest-complexity cases: largest series to date and literature review. Urology. 2015;85(6):1352-1359. 
6. Asimakopoulos AD, Miano R, Annino F, et al. Robotic radical nephrectomy for renal cell carcinoma: a systematic review. BMC Urol. 2014; $14: 75$

7. Rogers CG, Linehan WM, Pinto PA. Robotic nephrectomy for kidney cancer in a horseshoe kidney with renal vein tumor thrombus: novel technique for thrombectomy. J Endourol. 2008;22(8):1561-1563.

8. Romero FR, Muntener M, Bagga HS, Brito FA, Sulman A, Jarrett TW. Pure laparoscopic radical nephrectomy with level II vena caval thrombectomy. Urology. 2006;68(5):1112-1114.

9. Abaza R, Shabsigh A, Castle E, et al. Multi-institutional experience with robotic nephrectomy with inferior vena cava tumor thrombectomy. J Urol. Epub 2015 Nov 19.

10. Gill IS, Charles M, Abreu A, et al. Robotic level III inferior vena cava tumor thrombectomy: the initial series. J Urol. 2015;194(4):929-938.

11. Hemal AK, Kumar A. A prospective comparison of laparoscopic and robotic radical nephrectomy for T1-2N0M0 renal cell carcinoma. World J Urol. 2009;27(1):89-94.

12. Soga N, Kato M, Masui S, et al. Comparison of radical nephrectomy techniques in one center: minimal incision portless endoscopic surgery versus laparoscopic surgery. Int J Urol. 2008;15(11):1018-1021.

13. Park YH, Park JH, Jeong CW, Kim HH. Comparison of laparoendoscopic single-site radical nephrectomy with conventional laparoscopic radical nephrectomy for localized renal-cell carcinoma. J Endourol. 2010;24(6):997-1003.

14. Rogers C, Laungani R, Krane LS, Bhandari A, Bhandari M, Menon M. Robotic nephrectomy for the treatment of benign and malignant disease. BJU Int. 2008;102(11):1660-1665.

15. Boger M, Lucas SM, Popp SC, Gardner TA, Sundaram CP. Comparison of robot-assisted nephrectomy with laparoscopic and hand-assisted laparoscopic nephrectomy. JSLS. 2010;14(3):374-380.

16. Lorenzo EI, Jeong W, Oh CK, Chung BH, Choi YD, Rha KH. Robotics applied in laparoscopic kidney surgery: the Yonsei University experience of 127 cases. Urology. 2011;77(1):114-118.

17. Dogra PN, Abrol N, Singh P, Gupta NP. Outcomes following robotic radical nephrectomy: a single-center experience. Urol Int. 2012;89(1):78-82.

18. Pierorazio PM, Hyams ES, Lin BM, Mullins JK, Allaf ME. Laparoscopic radical nephrectomy for large renal masses: critical assessment of perioperative and oncologic outcomes of stage T2a and T2b tumors. Urology. 2012;79(3):570-575.

19. Ivey BS, Lucas SM, Meyer CA, et al. Conversions in laparoscopic renal surgery: causes and outcomes. J Endourol. 2011;25(7):1167-1173.

20. Aron M, Koenig P, Kaouk JH, Nguyen MM, Desai MM, Gill IS. Robotic and laparoscopic partial nephrectomy: a matched-pair comparison from a high-volume centre. BJU Int. 2008;102(1):86-92.

21. Hollenbeck BK, Taub DA, Miller DC, Dunn RL, Wei JT. National utilization trends of partial nephrectomy for renal cell carcinoma: a case of underutilization? Urology. 2006;67(2):254-259.

22. Mottrie A, De Naeyer G, Schatteman P, Carpentier P, Sangalli M, Ficarra V. Impact of the learning curve on perioperative outcomes in patients who underwent robotic partial nephrectomy for parenchymal renal tumours. Eur Urol. 2010;58(1):127-132.

23. Ahlering TE, Skarecky D, Lee D, Clayman RV. Successful transfer of open surgical skills to a laparoscopic environment using a robotic interface: initial experience with laparoscopic radical prostatectomy. J Urol. 2003;170(5):1738-1741.

24. DeLong JM, Shapiro O, Moinzadeh A. Comparison of laparoscopic versus robotic assisted partial nephrectomy: one surgeon's initial experience. Can J Urol. 2010;17(3):5207-5212.

25. Choi JE, You JH, Kim DK, Rha KH, Lee SH. Comparison of perioperative outcomes between robotic and laparoscopic partial nephrectomy: a systematic review and meta-analysis. Eur Urol. 2015;67(5): 891-901.

26. Kutikov A, Uzzo RG. The R.E.N.A.L. nephrometry score: a comprehensive standardized system for quantitating renal tumor size, location and depth. J Urol. 2009;182(3):844-853.
27. Ficarra V, Novara G, Secco S, et al. Preoperative aspects and dimensions used for an anatomical (PADUA) classification of renal tumours in patients who are candidates for nephron-sparing surgery. Eur Urol. 2009;56(5):786-793.

28. Simmons MN, Ching CB, Samplaski MK, Park CH, Gill IS. Kidney tumor location measurement using the C index method. J Urol. 2010; 183(5):1708-1713.

29. Leslie S, Gill IS, de Castro Abreu AL, et al. Renal tumor contact surface area: a novel parameter for predicting complexity and outcomes of partial nephrectomy. Eur Urol. 2014;66(5):884-893.

30. Klatte T, Ficarra V, Gratzke C, et al. A literature review of renal surgical anatomy and surgical strategies for partial nephrectomy. Eur Urol. 2015;68(6):980-992.

31. Simone G, Gill IS, Mottrie A, et al. Indications, techniques, outcomes, and limitations for minimally ischemic and off-clamp partial nephrectomy: a systematic review of the literature. Eur Urol. 2015;68(4):632-640.

32. Harke N, Schoen G, Schiefelbein F, Heinrich E. Selective clamping under the usage of near-infrared fluorescence imaging with indocyanine green in robot-assisted partial nephrectomy: a single-surgeon matchedpair study. World J Urol. 2014;32(5):1259-1265.

33. Akca O, Zargar H, Attalla K, et al. Possible detrimental effects of clamping main versus segmental renal arteries for the achievement of renal global ischemia during robot-assisted partial nephrectomy. J Endourol. 2015;29(7):785-790.

34. Desai MM, de Castro Abreu AL, Leslie S, et al. Robotic partial nephrectomy with superselective versus main artery clamping: a retrospective comparison. Eur Urol. 2014;66(4):713-719.

35. Becker F, Van Poppel H, Hakenberg OW, et al. Assessing the impact of ischaemia time during partial nephrectomy. Eur Urol. 2009;56(4):625-634.

36. Benway BM, Bhayani SB, Rogers CG, et al. Robot assisted partial nephrectomy versus laparoscopic partial nephrectomy for renal tumors: a multi-institutional analysis of perioperative outcomes. J Urol. 2009;182(3):866-872.

37. Benway BM, Bhayani SB, Rogers CG, et al. Robot-assisted partial nephrectomy: an international experience. Eur Urol. 2010;57(5): 815-820.

38. Dulabon LM, Kaouk JH, Haber GP, et al. Multi-institutional analysis of robotic partial nephrectomy for hilar versus nonhilar lesions in 446 consecutive cases. Eur Urol. 2011;59(3):325-330.

39. Spana G, Haber GP, Dulabon LM, et al. Complications after robotic partial nephrectomy at centers of excellence: multi-institutional analysis of 450 cases. J Urol. 2011;186(2):417-421.

40. Scoll BJ, Uzzo RG, Chen DY, et al. Robot-assisted partial nephrectomy: a large single-institutional experience. Urology. 2010;75(6): 1328-1334.

41. Haber GP, White WM, Crouzet S, et al. Robotic versus laparoscopic partial nephrectomy: single-surgeon matched cohort study of 150 patients. Urology. 2010;76(3):754-758.

42. Patel MN, Krane LS, Bhandari A, et al. Robotic partial nephrectomy for renal tumors larger than $4 \mathrm{~cm}$. Eur Urol. 2010;57(2):310-316.

43. Petros FG, Patel MN, Kheterpal E, et al. Robotic partial nephrectomy in the setting of prior abdominal surgery. BJU Int. 2011;108(3):413-419.

44. Naeem N, Petros F, Sukumar S, et al. Robot-assisted partial nephrectomy in obese patients. J Endourol. 2011;25(1):101-105.

45. Wang Y, Ma X, Huang Q, et al. Comparison of robot-assisted and laparoscopic partial nephrectomy for complex renal tumours with a RENAL nephrometry score $\geq 7$ : peri-operative and oncological outcomes. BJU Int. 2015;117(1):126-130.

46. Ting F, Savdie R, Chopra S, Yuen C, Brenner P. Early experience in Da Vinci Robot-assisted partial nephrectomy: an Australian single centre series. Minim Invasive Surg. 2015;2015:671267.

47. Kim JH, Park YH, Kim YJ, et al. Perioperative and long-term renal functional outcomes of robotic versus laparoscopic partial nephrectomy: a multicenter matched-pair comparison. World J Urol. 2015;33(10): $1579-1584$ 
48. Masson-Lecomte A, Bensalah K, Seringe E, et al. A prospective comparison of surgical and pathological outcomes obtained after robot-assisted or pure laparoscopic partial nephrectomy in moderate to complex renal tumours: results from a French multicentre collaborative study. BJU Int. 2013;111(2):256-263.

49. Aboumarzouk OM, Stein RJ, Eyraud R, et al. Robotic versus laparoscopic partial nephrectomy: a systematic review and meta-analysis. Eur Urol. 2012;62(6):1023-1033.

50. Bi L, Zhang C, Li K, et al. Robotic partial nephrectomy for renal tumors larger than $4 \mathrm{~cm}$ : a systematic review and meta-analysis. PLoS One. 2013;8(10):e75050.

51. Reyes JM, Smaldone MC, Uzzo RG, Viterbo R. Current status of robot-assisted partial nephrectomy. Curr Urol Rep. 2012;13(1): 24-37.

52. Lane BR, Gill IS. 7-year oncological outcomes after laparoscopic and open partial nephrectomy. J Urol. 2010;183(2):473-479.

53. Gorin MA, Ball MW, Pierorazio PM, et al. Outcomes and predictors of clinical T1 to pathological T3a tumor up-staging after robotic partial nephrectomy: a multi-institutional analysis. J Urol. 2013;190(5) 1907-1911.

54. Ficarra V, Rossanese M, Gnech M, Novara G, Mottrie A. Outcomes and limitations of laparoscopic and robotic partial nephrectomy. Curr Opin Urol. 2014;24(5):441-447.

55. Khalifeh A, Autorino R, Eyraud R, et al. Three-year oncologic and renal functional outcomes after robot-assisted partial nephrectomy. Eur Urol. 2013;64(5):744-750.

56. Lista G, Buffi NM, Lughezzani G, et al. Margin, ischemia, and complications system to report perioperative outcomes of robotic partial nephrectomy: a European Multicenter Observational Study (EMOS project). Urology. 2015;85(3):589-595.

57. Clavien PA, Barkun J, de Oliveira ML, et al. The Clavien-Dindo classification of surgical complications: five-year experience. Ann Surg. 2009;250(2):187-196.

58. Zargar H, Allaf ME, Bhayani S, et al. Trifecta and optimal perioperative outcomes of robotic and laparoscopic partial nephrectomy in surgical treatment of small renal masses: a multi-institutional study. BJU Int. 2014;116(3):407-414.

59. Tanagho YS, Kaouk JH, Allaf ME, et al. Perioperative complications of robot-assisted partial nephrectomy: analysis of 886 patients at 5 United States centers. Urology. 2013;81(3):573-579.

60. Gill IS, Kavoussi LR, Lane BR, et al. Comparison of 1,800 laparoscopic and open partial nephrectomies for single renal tumors. J Urol. 2007;178:41-46.

61. Ficarra V, Bhayani S, Porter J, et al. Predictors of warm ischemia time and perioperative complications in a multicenter, international series of robot-assisted partial nephrectomy. Eur Urol. 2012;61(2): 395-402.

62. Kim EH, Larson JA, Figenshau M, Figenshau RS. Perioperative complications of robot-assisted partial nephrectomy. Curr Urol Rep. 2014;15(1):377.

63. Siegel RL, Miller KD, Jemal A. Cancer statistics, 2015. CA Cancer J Clin. 2015;65(1):5-29.

64. Simone G, Papalia R, Guaglianone S, et al. Laparoscopic versus open nephroureterectomy: perioperative and oncologic outcomes from a randomised prospective study. Eur Urol. 2009;56(3):520-526.

65. Rose K, Khan S, Godbole H, Olsburgh J, Dasgupta P, Group GSaSTR. Robotic assisted retroperitoneoscopic nephroureterectomy first experience and the hybrid port technique. Int J Clin Pract. 2006;60(1):12-14

66. Lee Z, Cadillo-Chavez R, Lee DI, Llukani E, Eun D. The technique of single stage pure robotic nephroureterectomy. J Endourol. 2013; 27(2):189-195.

67. Yang CK, Chung SD, Hung SF, et al. Robot-assisted nephroureterectomy for upper tract urothelial carcinoma: the Taiwan Robot Urological Surgery Team (TRUST) experience. World J Surg Oncol. $2014 ; 12: 219$.
68. Aboumohamed AA, Krane LS, Hemal AK. Oncologic outcomes following robot-assisted laparoscopic nephroureterectomy with bladder cuff excision for upper tract urothelial carcinoma. J Urol. 2015;194(6):1561-1566.

69. Xylinas E, Rink M, Cha EK, et al. Impact of distal ureter management on oncologic outcomes following radical nephroureterectomy for upper tract urothelial carcinoma. Eur Urol. 2014;65(1):210-217.

70. Pugh J, Parekattil S, Willis D, Stifelman M, Hemal A, Su LM. Perioperative outcomes of robot-assisted nephroureterectomy for upper urinary tract urothelial carcinoma: a multi-institutional series. BJU Int. 2013;112(4):E295-E300.

71. Martin GL, Guise AI, Bernie JE, Bargman V, Goggins W, Sundaram CP. Laparoscopic donor nephrectomy: effects of learning curve on surgical outcomes. Transplant Proc. 2007;39(1):27-29.

72. Su LM, Ratner LE, Montgomery RA, et al. Laparoscopic live donor nephrectomy: trends in donor and recipient morbidity following 381 consecutive cases. Ann Surg. 2004;240(2):358-363.

73. Horgan S, Galvani C, Gorodner MV, et al. Effect of robotic assistance on the "learning curve" for laparoscopic hand-assisted donor nephrectomy. Surg Endosc. 2007;21(9):1512-1517.

74. Giacomoni A, Di Sandro S, Lauterio A, et al. Evolution of robotic nephrectomy for living donation: from hand-assisted to totally robotic technique. Int J Med Robot. 2014;10(3):286-293.

75. Giacomoni A, Di Sandro S, Lauterio A, et al. Initial experience with robotassisted nephrectomy for living-donor kidney transplantation: feasibility and technical notes. Transplant Proc. 2013;45(7):2627-2631.

76. Hubert J, Renoult E, Mourey E, Frimat L, Cormier L, Kessler M. Complete robotic-assistance during laparoscopic living donor nephrectomies: an evaluation of 38 procedures at a single site. Int J Urol. 2007;14(11):986-989.

77. Oberholzer J, Giulianotti P, Danielson KK, et al. Minimally invasive robotic kidney transplantation for obese patients previously denied access to transplantation. Am J Transplant. 2013;13(3): 721-728.

78. Boggi U, Signori S, Vistoli F, et al. Current perspectives on laparoscopic robot-assisted pancreas and pancreas-kidney transplantation. Rev Diabet Stud. 2011;8(1):28-34.

79. Menon M, Sood A, Bhandari M, et al. Robotic kidney transplantation with regional hypothermia: a step-by-step description of the Vattikuti Urology Institute-Medanta technique (IDEAL phase 2a). Eur Urol. 2014;65(5):991-1000.

80. Tsai MK, Lee CY, Yang CY, Yeh CC, Hu RH, Lai HS. Robotassisted renal transplantation in the retroperitoneum. Transpl Int. 2014;27(5):452-457.

81. Tzvetanov I, Bejarano-Pineda L, Giulianotti PC, et al. State of the art of robotic surgery in organ transplantation. World J Surg. 2013;37(12):2791-2799.

82. Modi P, Pal B, Modi J, et al. Retroperitoneoscopic living-donor nephrectomy and laparoscopic kidney transplantation: experience of initial 72 cases. Transplantation. 2013;95(1):100-105.

83. Tzvetanov I, D’Amico G, Benedetti E. Robotic-assisted kidney transplantation: our experience and literature review. Curr Transplant Rep. 2015;2(2):122-126.

84. Lynch RJ, Ranney DN, Shijie C, Lee DS, Samala N, Englesbe MJ. Obesity, surgical site infection, and outcome following renal transplantation. Ann Surg. 2009;250(6):1014-1020.

85. Sood A, Jeong W, Ahlawat R, et al. Minimally invasive renal autotransplantation. J Surg Oncol. 2015;112(7):717-722.

86. Gordon ZN, Angell J, Abaza R. Completely intracorporeal robotic renal autotransplantation. J Urol. 2014;192(5):1516-1522.

87. Gettman MT, Neururer R, Bartsch G, Peschel R. Anderson-Hynes dismembered pyeloplasty performed using the da Vinci robotic system. Urology. 2002;60(3):509-513.

88. Lucas SM, Mellon MJ, Erntsberger L, Sundaram CP. A comparison of robotic, laparoscopic and open partial nephrectomy. JSLS. 2012 ; 16(4):581-587. 
89. Cestari A, Buffi NM, Lista G, et al. Retroperitoneal and transperitoneal robot-assisted pyeloplasty in adults: techniques and results. Eur Urol. 2010;58(5):711-718.

90. Samarasekera D, Stein RJ. Robotic-assisted laparoscopic approaches to the ureter: pyeloplasty and ureteral reimplantation. Indian J Urol. 2014;30(3):293-299.

91. Ukimura O, Nakamoto M, Gill IS. Three-dimensional reconstruction of renovascular-tumor anatomy to facilitate zero-ischemia partial nephrectomy. Eur Urol. 2012;61(1):211-217.

92. Shao P, Tang L, Li P, et al. Application of a vasculature model and standardization of the renal hilar approach in laparoscopic partial nephrectomy for precise segmental artery clamping. Eur Urol. 2013;63(6):1072-1081.

93. Komai Y, Sakai Y, Gotohda N, Kobayashi T, Kawakami S, Saito N. A novel 3-dimensional image analysis system for case-specific kidney anatomy and surgical simulation to facilitate clampless partial nephrectomy. Urology. 2014;83(2):500-506.

94. Hughes-Hallett A, Pratt P, Mayer E, Martin S, Darzi A, Vale J. Image guidance for all-TilePro display of 3-dimensionally reconstructed images in robotic partial nephrectomy. Urology. 2014;84(1):237-242.

95. Isotani S, Shimoyama H, Yokota I, et al. Feasibility and accuracy of computational robot-assisted partial nephrectomy planning by virtual partial nephrectomy analysis. Int J Urol. 2015;22(5):439-446.
96. Pervez A, Ahmed K, Thompson S, Elhage O, Khan MS, Dasgupta P. Image guided robotic surgery: current evidence for effectiveness in urology. Arch Ital Urol Androl. 2014;86(4):245-248.

97. Alenezi AN, Karim O. Role of intra-operative contrast-enhanced ultrasound (CEUS) in robotic-assisted nephron-sparing surgery. $J$ Robot Surg. 2015;9(1):1-10.

98. Kaouk JH, Goel RK. Single-port laparoscopic and robotic partial nephrectomy. Eur Urol. 2009;55(5):1163-1169

99. White WM, Haber GP, Goel RK, Crouzet S, Stein RJ, Kaouk JH. Single-port urological surgery: single-center experience with the first 100 cases. Urology. 2009;74(4):801-804.

100. Buffi NM, Lughezzani G, Fossati N, et al. Robot-assisted, single-site, dismembered pyeloplasty for ureteropelvic junction obstruction with the new da Vinci platform: a stage 2a study. Eur Urol. 2015;67(1): 151-156.

101. Haber GP, White MA, Autorino R, et al. Novel robotic da Vinci instruments for laparoendoscopic single-site surgery. Urology. 2010;76(6):1279-1282.

102. Rogers CG, Menon M, Weise ES, et al. Robotic partial nephrectomy: a multiinstitutional analysis. J Robotic Surg. 2008;2:141-143.

\section{Dovepress}

\section{Publish your work in this journal}

Robotic Surgery: Research and Reviews is an international, peer reviewed, open access, online journal publishing original research, commentaries, reports, and reviews on the theory, use and application of robotics in surgical interventions. Articles on the use of supervisorycontrolled robotic systems, telesurgical devices, and shared-control

systems are invited. The manuscript management system is completely online and includes a very quick and fair peer review system, which is all easy to use. Visit http://www.dovepress.com/testimonials.php to read real quotes from published authors. 